\title{
Covering a Triangular Number with Pentagonal Numbers
}

\section{Günhan Caglayan}

Proposition. For $n \in \mathbb{N}$, the following identity holds:

$$
T_{6 n-1}=12 P_{n}+3 n,
$$

where $T_{n}$ is the nth triangular number, and $P_{n}$ is the nth pentagonal number.
Mathematics Department New Jersey City University Jersey City, NJ 07305

USA

e-mail: gcaglayan@njcu.edu

PROOF. The proof is demonstrated for $n=5$.
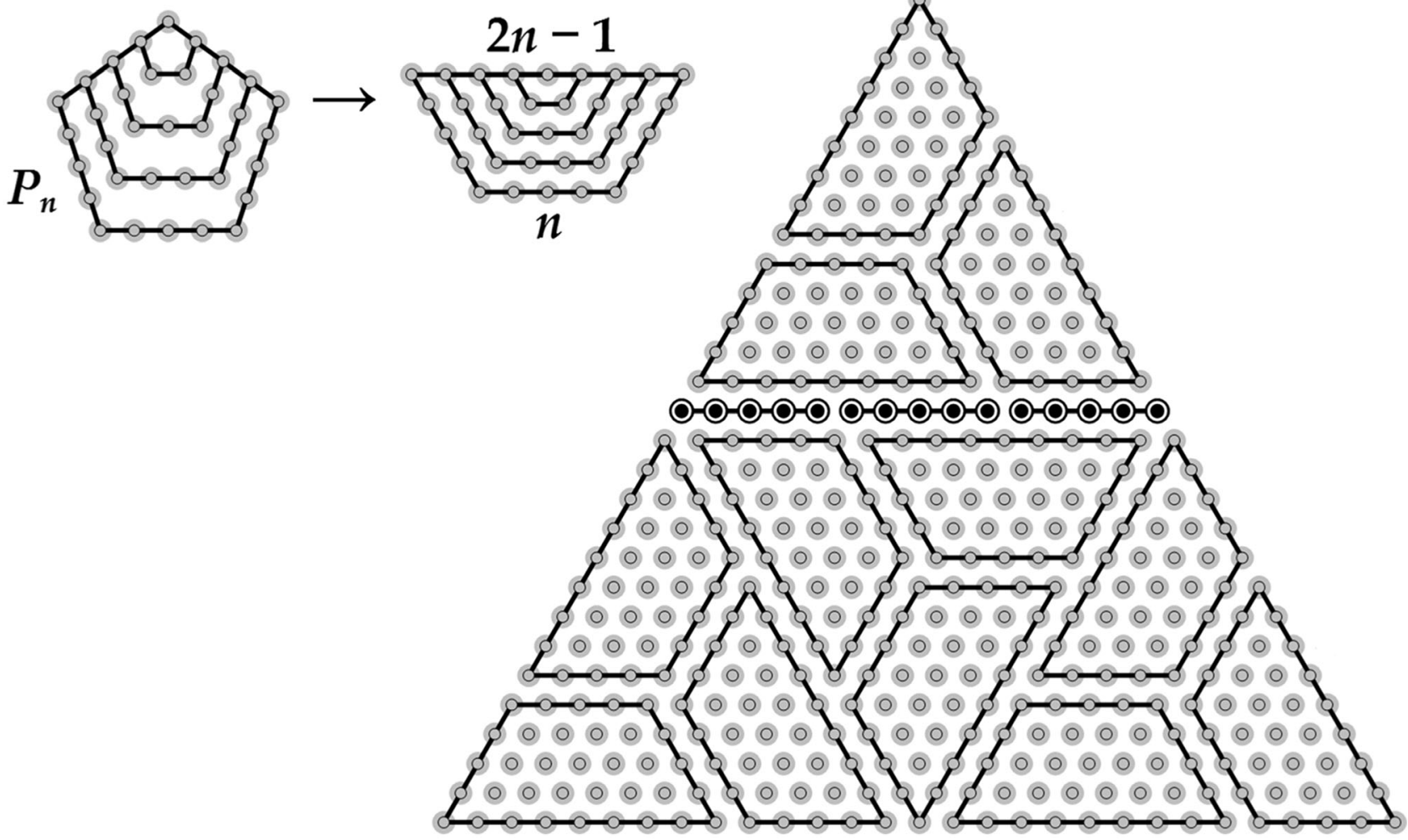

Publisher's Note Springer Nature remains neutral with regard to jurisdictional claims in published maps and institutional affiliations. 